\title{
Research Paper: Investigation of the Psychosocial Factors Affecting High Risk Driving Behaviors in Adolescents in crossnark the City of Tehran, 2014
}

Seyyed Mohammad Hossein Javadi', Siyamak Tahmasebi ${ }^{*}$, Tahereh Azari Arghun ${ }^{3}$, Forugh Edrisi ${ }^{4}$, Esmail Soltani ${ }^{5}$, Sa'adollah Hashemi $^{6}$, Alireza Tajlili', Nader Rahmani ${ }^{8}$

1. Department of Social Work, University of Social Welfare and Rehabilitation Sciences, Tehran, Iran.

2. Department of Preschool, University of Social Welfare and Rehabilitation Sciences, Tehran, Iran.

3. Iran Association of Social Workers, Tehran, Iran.

4. Department of Psychology, Faculty of Education and Psychology, Shahid Beheshti University, Tehran, Iran.

5. Research Center for Psychiatry and Behavior Science, Shiraz University of Medical Sciences, Shiraz, Iran.

6. Department of Psychology, Faculty of Psychology and Educational Sciences, Allameh Tabataba'i University, Tehran, Iran.

7. Country Coordinating Mechanism Committee, The Global Fund, Tehran, Iran.

8. Department of Traffic Safety, Faculty of Guidance and Driving Sciences, Amin Police University, Tehran, Iran.

\begin{tabular}{|c|c|}
\hline $\begin{array}{l}\text { Use your device toscan } \\
\text { and read the article online }\end{array}$ & Citation: Javadi SMH, Tahmasebi S, Azari Arghun T, Edrisi F, Soltani E, Hashemi S, et al. Investigation of the Psychosocial \\
\hline 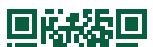 & Factors Affecting High Risk Driving Behaviors in Adolescents in the City of Tehran, 2014. Health in Emergencies and Disasters \\
\hline Fing & Quarterly. 2017; 3(1):39-50. https://doi.org/10.29252/NRIP.HDQ.3.1.39 \\
\hline 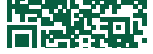 & doi): https://doi.org/10.29252/NRIP.HDQ.3.1.39 \\
\hline
\end{tabular}

Article info:

Received: 11 May 2017

Accepted: 24 Jul. 2017

\section{Keywords:}

High risk behaviors,

Psychological social factors,

Adolescents

\section{A B S T R A C T}

Background: Driving accidents are among the most important causes of mortality in the world in recent years. In Iran, especially in major cities such as Tehran, this issue has become a prevalent social problem. More importantly, adolescents and young people constitute the majority of the victims of traffic accidents. Therefore, the aim of the present study was to investigate the psychosocial dimensions affecting high risk driving behaviors in adolescents in the age group between 12 to 17 years, in the city of Tehran.

Materials and Methods: The present study has taken a quantitative (correlation) approach by selecting a sample of 537 adolescents aged between 12 to 17 years and the psychosocial factors affecting high risk driving behaviors were assessed. The samples were selected by a Stratifiedcluster method from the insurance company, hospitals and education correctional centers.

Results: Our study demonstrate that among psychological factors, three determinants, namely national religious identity, attitude toward laws and rules, and aggression were able to predict high risk behaviors in boys group with coefficient of $\mathrm{B}, 0.24$, and 0.16 , respectively; while the strongest predictor of high risk behavior is national religious identity. On the other hand, in the girls' group, two factors, namely autocratic parenting and attitude toward law and rules were able to predict high risk behaviors with coefficients of $\mathrm{B}, 0.19$, and 0.18 , respectively; while the strongest predictor was the autocratic style of parenting. Among social factors, our findings show that participation in the plan to cooperate with traffic police with coefficients of Beta 0.26 and 0.21 , respectively, is the strongest predictor of high risk behavior in adolescent boys and girls.

Conclusion: Among predictor variables aggression, law breaking behavior, and national religious identity can better predict driving accidents, attitude toward law, and high risk behaviors. Aggression, attitude, and law breaking behavior are considered as abnormal behaviors that lead to legal problems, delinquencies, substance abuse and other destructive behaviors among adolescents and consequently cause damage, injury and disabilities in themselves and others. Moreover, involvement in aggressive behaviors can play a critical role in creating and exacerbating new behavioral problems in adolescents, and those problems are carried over immutably at the later stages of their life.

\section{* Corresponding Author:}

Siyamak Tahmasebi, PhD

Address: Department of Preschool, University of Social Welfare and Rehabilitation Sciences, Tehran, Iran

E-mail: siyamak.tahmasebi@gmail.com 


\section{Introduction}

$\mathbf{T}$

he problem that has put at risk the physical integrity and general comfort of people in big cities and has attracted public attention is the issue of occurrence and increase in crime incidence caused by driving violations. This has raised concerns and efforts are on by the authorities to identify and control the causes of these accidents. It is estimated that each year approximately 5 million people lose their lives around the world because of accidents and tens of times of that number are faced with disabilities [1]. In developing countries, driving accidents are the most important causes of mortality, the primary cause of mortality for people below the age of forty, and the third cause of mortality among all age groups. Each day thousands of people lose their lives on roads and highways due to driving accidents and these accidents not only result in the death of healthy individuals in the best period of their lives as regards effectiveness and competence of their functions in life and also their health, but it also imposes many financial and psychological sufferings on families [2].

Iran is one of the countries that have witnessed the most cases of mortality and injury resulting from driving accidents and this situation in comparison with other countries is very worrisome [3]. Studies show that in Iran, youngsters and adolescents are involved in highest numbers of driving accidents among all age groups [4].

Many reasons have been put forth for the high rate of driving accidents among young people. As compared with other age groups, adolescents and youngsters drive with much faster speeds exceeding the legally allowed level. They are less reluctant than others to maintain the minimum distance that should be kept between the car they are driving and the cars ahead or behind them, and more than others they try, through unauthorized manner, to overtake other cars while driving. Young people usually estimate the risk inherent in some traffic situations less than what it really is; and they consider their ability in driving skills more than it really is and assume themselves immune to unfavorable consequences. In addition, adolescents and youngsters attempt high risk driving in order to demonstrate their independence, disobedience toward sources of authority, obtaining the approval of their peers, and satisfy the need for stimulation [5].

Young and adolescent drivers are more exposed to the risk of driving accident than old people and other age groups [6]. In Iran, statistical examination of driving accidents victims between the years 2006 to 2009 shows that approximately $31 \%$ of victims are youngsters [4]. Furthermore, data indicate that the rate of mortality and injury in adolescents are much higher than other age groups. Adolescents and youngsters, who are in the early years of the second decade of their life, especially the boys have the highest rate of driving accidents as compared with other age groups [6].

Studies show that in 2011, the province of Tehran with $11.3 \%$ of the total population of the country had the highest number of injuries from driving accidents [3]. Also, in the year 2013, nearly five thousand Iranian youths were killed due to driving accidents [7]. Results of studies on those injured in traffic accidents in Iran are very worrisome. Apart from the cases mentioned earlier, traffic accidents are the third major cause of women becoming widowed and consequently become head of their household and covered by the welfare organization [8]. Additionally, the leading cause of mortality of children and adolescents in Iran is driving accidents [7].

Studies on traffic accidents conducted in Iran and abroad demonstrate that the attitude of adolescents toward driving is an important factor that determines their driving style. Driving style can be termed as the method by which an individual chooses to drive. Generally, different attitude factors such as positive or negative evaluation of the behavior's conduct, a person's perception of social pressure related to what he/she is doing, person's perception of the easiness or difficulty of his/her conduct of driving, person's perception of how many important people display the same behavior in their lives, all of these factors can contribute to driving accidents. A person's outlook toward his/her own fate is also a factor that can play a role in driving accidents.

The planned behavior theory focuses on behavior and can respond to the question that why a driver chooses a special kind of behavior. According to planned behavior theory people's attitude toward behavior, mental condition, and their perceived behavioral control determine their intention to engage in a behavior. According to this theory, the intent to engage in a behavior is predicted by the following three factors: 1 . attitude; 2 . social norms; and 3. perceived behavioral control [12].

In the model proposed by Shope and Bingham in 2008, personality factors (inclination toward risk, aggression, being hostile, sensitivity toward pressure from peers, tolerance toward deviations, and seeking stimulations), behavioral factors (anti social behavior, substance abuse, seeking risk, behavioral difficulties, and driving before obtaining driving license), growth factors (physical 
hormones, energy, sleep, psychosocial and emotional factors), social factors (identity and sexuality), driving ability (awareness, experience and skill), demographic factors (age, gender, job status, education and life situation), environment perception (parents' norms, expected behaviors, conflict with parents, peers' norms control, social norms, media publicity, entertainment, risk perception), and driver's social and physical environment (night or darkness, road and climate conditions, vehicle capability, type of vehicle, driver's companion based on age, the material of the drug and drug abuse, purpose of driving) affect the youngsters' driving behavior (speed, unsafe overtaking of other cars while driving, failure to observe authorized distance from the vehicles ahead or behind, harmful driving, fatigue, distress, and failure to use the safety belt) [13].

Based on the model by Morrongiello and Lessard (2007) personal characteristics (age, gender, behavioral attitudes, activity experience, values and personal motives, temperament), familial and parental factors (socialization duties, learning duties, parenting styles, the influence of siblings, parental models), and social/situational factors (verbal encouragements, observational learning effects, encouraging motivational situations) in seeking risk or avoiding accident, are in interaction with one another [14].

Evidently, one of the most important factors that lead to driving accidents is high risk driving. Driving behavior is also part of the general culture of the people of a community, because it is related to values, habits, attitudes and other factors and is conveyed from one generation to the next. Therefore, the rate of accidents in a society can be reduced when high risk driving and the factors affecting it in a particular culture are investigated.

In the fields of health, habits or actions that expose a person to illness or health-related problems are referred to as dangerous or risky behaviors. According to this definition, driving behaviors that endanger the health of those who use roads and streets are dangerous. High risk behavior means committing two or more violations of driving norms and rules that cause endangering other people or vehicles. Examples of high risk driving include: using mobile phone while driving, failure to observe suitable distance with the vehicle in front or behind, failure to drive between lines, failure to fasten the safety belt, driving over the speed limit, unlawful overtaking of other cars while driving, sudden change in driving direction, deviation toward the lane on the left of them, doing spiral or zigzag moves while driving in an angry mood, and driving when fatigued and drowsy.
In the light of above facts, studying high risk behaviors as important health and social problems for adolescents is of special importance. The significance of paying attention to the health of this group of people, particularly in relation to accidents, is essential as adolescents and youngsters are capital for the future of a nation and need comprehensive attention. Considering the importance of human lives and Tehran being the financial capital of the nation, it is paramount to pay comprehensive attention to prevent and reduce the rate of driving accidents in the city. Therefore the present study aimed at investigating psychosocial factors that influence the emergence of high risk behaviors in adolescents between the ages 12 and 17 years in the city of Tehran.

\section{Materials and Methods}

\section{Research plan}

The layout of the present study is quantitative (correlation) in which by selecting a sample of individuals consisting of boys and girls in the age group of 12-17 years we investigated the psychosocial factors affecting high risk driving behavior.

\section{Population and sampling}

The entire statistical population in this research comprised of adolescents in the age group of 12-17 years involved in driving accidents, who had been referred to hospitals, insurance centers, and education correctional centers. Considering that the model in this study was designed using LISRELL software, the sample volume should be compatible with the number of variables measured by the tools and their subscales, which means that maximum 15 persons are needed for each measured variable. Accordingly, minimum 200 persons were needed as a sample size for each group of girls and boys in this study. Keeping in mind the likelihood that some questionnaires might not be completed by the respondents, 537 questionnaires were prepared for 327 boys and 210 girls selected based on the inclusion criteria.

The sampling in this research was conducted through stratified sampling method from insurance centers, hospitals, and education correctional centers. The number of samples of each center was determined relative to the volume of referrals to the said center and residents of that center. The sample selection method was done in a way so that the number of referrals and residents of each center was estimated on a daily basis and divided by the number of samples selected from that center. Subsequently, after a certain interval, the samples were in- 
troduced by the center's expert to the researcher. In case anyone was not inclined to respond, the sample next to that was substituted for the previous one.

Inclusion criteria for the research were those within the age of 12 to 17 years with minimum education to fill out the questionnaires, having a history of traffic accidents as a pedestrian, motorcycle rider, bicycle rider, skater, and even driver. The exclusion criteria were having a record of psychological illness, mental or physical backwardness, and lack of having sufficient education to fill out the questionnaires.

\section{Assessment tools}

Data collection tool in this research is the questionnaire. The questionnaires include: Demographics Questionnaire (Table 1), Child Behavior Check List (CBCL), Parenting Styles Questionnaire, Family Assessment Device (FAD), Eysenck's Personality Questionnaire (adolescent form), Aggression Questionnaire, and Coopersmith SelfEsteem Inventory (1967).

\section{Demographics Questionnaire}

Subject of questions include age, gender, education level, background in driving accidents, date of accident within the week, hour of the accident within the day and/ or night, type of vehicle, location of accident, safety belt, participation in the plan to cooperate with traffic police, the participant's attitude toward laws and rules and driving, adolescents' attitude toward laws and rules, lifestyle and other demographic characteristics. Scoring of some answers to the questionnaires was done on a 5-point Likert scale (e.g., very few score 1 and very much score 5), some of the questions were rated in the form of yes/no, and the rest in the form of quality.

\section{Child Behavior Check List (CBCL)}

This checklist developed by Achenbach is one of the most famous and most applied comprehensive scales with regard to children's behavioral problems (a, b, c 1991). The checklist has two sections: skills and emotional behavioral problems. Achenbach obtained its reliability through Cronbach and it was equal to 0.46 to 0.96. Yazdkhasti and Arizi (2011) attempted to investigate the standardization of three versions of checklists, namely child, father/mother, and teacher in the city of Isfahan. These researchers obtained the Cronbach's alpha of the child version to be 0.82 [15]. Structural validity has been obtained through the correlation of subscales of the behavioral-emotional problems section, while the overall score of this section in the children version being 0.51 to 0.85 and the correlation of skills' subscales being 0.64 to 0.87 .

\section{Parenting Styles Questionnaire}

This questionnaire was designed by Baumrind in 1972 and contains 30 questions [16]. This questionnaire assesses three styles of parenting. Scoring is based on 5- point Likert scale. Buri (1991) by using the retest method has reported the reliability of these tools with regard to parents. Scores for the permissive style were 0.81 (mother) and 0.77 (father), for the authoritarian style 0.86 (mother) and 0.85 (father), and for the authoritative style 0.78 (mother) and 0.88 (father). He also affirmed the diagnostic validity of this questionnaire. Accordingly, the authoritarian style of the father has a reverse relation with the permissive style $(-0.38)$ and his authoritative style (-0.48), and the authoritarianism of the mother also has a reverse relation with the permissive style (-0.50) and her authoritative style (-0.52) [17]. In 1995, Esfandiari reported the reliability of this questionnaire to be favorable [9].

\section{Family Assessment Device (FAD)}

This questionnaire has been prepared by Epstein, Baldwin, and Bishop (1983) based on McMasters model and includes 60 questions that have been designed to assess family function in various dimensions [18]. These dimensions include problem resolution, communication, roles, emotional and mental response, emotional participation, and behavior control. After preparation by Epstein et al. [18] this test was conducted on a sample of 503 people and its alpha subscale coefficients were between 0.74 and 0.94. In Iran, Najarian (1995) and Golizadeh (2004) have reported that the reliability of this test was appropriate [19]. In this research, the seventh subscale or general function was used.

\section{Eysenck's Personality Questionnaire (adolescent form)}

This questionnaire was developed by Eysenck (1975) to assess the personality of adolescents between the ages of 12 and 18 and contains 80 questions where response was given in the form of yes or no. In Iran, Rahiminezhad using the retest method has reported the reliability coefficient of this questionnaire for extroversion indicators to be 0.92 , lie detector 0.88 , neuroticism 0.86 , and psychosis 0.72 . The retest reliability coefficients reported by the original developer of the test are also numbers between 0.76 for the neuroticism indicator and maximum 0.90 for the extroversion indicator [20]. 


\section{Aggression Questionnaire}

This questionnaire has been prepared by Hajati (2008) [10] based on an integration of Eysenck aggression test and diagnostic interview with children and adolescents and using diagnostic and statistical manual for mental disorder (DSM-IV). This questionnaire contains 24 questions and its scoring is in the form of Likert. Cronbach's alpha for a 50 person sample was determined to be 0.83 . The retest reliability with 3 weeks interval was obtained as being equal to 0.70 [10].

\section{Coopersmith self-esteem inventory (1967)}

This questionnaire was prepared and compiled by Coopersmith [21] and includes 58 articles, of which 8 articles are lie detectors and its scoring method is in the form of zero and one. Several reports have validated the reliability of this method. This questionnaire has the children and adolescents forms and its reliability in Cronbach method has been equal to 0.82 [22]. Also, to measure high risk behaviors of adolescents, from the list of questions in the questionnaire some items such as passing the red light, using the safety belt, using the safety helmet, joking in the street, using the pedestrian overhead bridge, and walking on foot on the highway have been selected. All of these items assess high risk behaviors and comprise the high risk factors. The validity and reliability of this questionnaire have been confirmed by authorities on the subject.

Before entering the stage for testing the hypotheses and conceptual models of the research, To ensure the correctness of independent variables measurement model (personality factors, parenting, lifestyle, family function, psychological health) and dependent variable (driving violations), the first and second order Confirmatory Factor Analysis (CFA) technique has been used. Accordingly, some of the factors have been excluded from the analysis due to their low significant coefficients.

\section{Method}

The questionnaires and the interview were carried out by young volunteers from the Red Crescent Society. Those volunteers were postgraduate students studying in related fields such as psychology and social work. To execute their task, necessary training was provided to them through three sessions and after ensuring that they have the required competence, the study was conducted in coordination with related organizations such as hospitals, insurance centers, and education correctional centers. During implementation, two of the re- search colleagues were supervising the examiners and questionnaires were handed over to the colleagues as soon as they were completed.

In this research, the descriptive statistical method (median, standard deviation, and chart) and inferential statistics which includes Yuman Whitney, Kruskal Wallis, Spearman and Pearson correlation coefficient and simultaneous regression, stepwise regression, and structural equation model were used to analyze the quantitative data. Quantitative data analysis was carried out using SSP and Lisrel software.

\section{Results}

High risk model in boys and girls groups (findings of stepwise regression analysis)

Multiple regression method (stepwise) was used to answer the question as to what is the level of contribution of each of the parameters such as personality factors, behavioral problems, self-esteem, aggression, and demographic factors to the high risk behaviors of boys and girls aged 12-17 years, and what percentage of these factors predict the high risk behavior variance. Considering that the research questions aimed at identifying the contribution of each of the above mentioned factors separately in the boys and girls groups, separate regression analysis was carried out for those two groups and eventually the models obtained in the two groups were compared with one another in terms of fit indicators (Table 2). It is noteworthy to mention that stepwise regression is the order of input of variables into the analysis based on zero order correlation coefficient.

Predictors were Anxiety/depression, seclusion/depression, physical complaints, social problems, thinking problems, problems of attention, law breaking behavior, aggressive behavior, other problems, type of vehicle with which the accident has occurred, time of accident, education, age, the type of clothes used, being member of assistant traffic police, use of computer game while driving, bicycle riding on highways. The dependent variable was high risk behavior.

Psychological variables in this research include personality factor variables, behavioral problems, parental style, aggression, national religious identity and selfesteem. Stepwise regression was used for personality variables, behavioral problems, and parental style in both boys and girls groups. Afterwards, all of the predictor variables entered the equation so that based on the 
Table 1. Demographic characteristics

\begin{tabular}{|c|c|c|}
\hline Variable & Percent & Frequency \\
\hline \multicolumn{3}{|c|}{ Gender (N=537) } \\
\hline Boy & 60.9 & 327 \\
\hline Girl & 39.1 & 210 \\
\hline \multicolumn{3}{|c|}{ Using pedestrian overhead bridge when crossing the street $(N=537)$} \\
\hline Always & 19.6 & 105 \\
\hline Sometimes & 46.4 & 249 \\
\hline Rarely & 34.1 & 183 \\
\hline \multicolumn{3}{|c|}{ Attention to the red light for crossing the street $(N=537)$} \\
\hline Always & 31.1 & 167 \\
\hline Sometimes & 39.1 & 210 \\
\hline Rarely & 29.8 & 160 \\
\hline \multicolumn{3}{|c|}{ Participation in the plan to cooperate with the traffic police $(537=\mathrm{N})$} \\
\hline Yes & 48.6 & 261 \\
\hline No & 51.4 & 276 \\
\hline \multicolumn{3}{|c|}{ Using safety belt $(\mathrm{N}=537)$} \\
\hline Always & 28.3 & 152 \\
\hline Sometimes & 42.3 & 227 \\
\hline Rarely & 29.4 & 158 \\
\hline \multicolumn{3}{|c|}{ Using computer games related to driving $(\mathrm{N}=537)$} \\
\hline Yes & 67.2 & 361 \\
\hline No & 32.8 & 176 \\
\hline \multicolumn{3}{|c|}{ Using safety helmet while riding on motorcycle $(N=537)$} \\
\hline Always & 12.3 & 66 \\
\hline Sometimes & 35.8 & 192 \\
\hline Rarely & 52.0 & 279 \\
\hline \multicolumn{3}{|c|}{ Joking with friends on the street $(\mathrm{N}=537)$} \\
\hline Always & 34.1 & 183 \\
\hline Sometimes & 38.4 & 206 \\
\hline Rarely & 27.6 & 148 \\
\hline \multicolumn{3}{|c|}{ Bicycle riding on highways ( $N=537$ ) } \\
\hline Yes & 29.2 & 157 \\
\hline No & 70.8 & 380 \\
\hline \multicolumn{3}{|c|}{ Crossing the middle of a highway (on foot) $(\mathrm{N}=537)$} \\
\hline Yes & 48.8 & 262 \\
\hline No & 51.2 & 275 \\
\hline
\end{tabular}


Table 2. Findings of stepwise regression for psychological and social variables in boys and girls group

\begin{tabular}{|c|c|c|c|c|c|c|}
\hline & \multirow{2}{*}{ Model } & \multicolumn{2}{|c|}{ Non Standardized Coefficients } & \multirow{2}{*}{$\begin{array}{c}\text { Standardized Coefficients } \\
\text { Beta Coefficient }\end{array}$} & \multirow{2}{*}{$\mathbf{t}$} & \multirow{2}{*}{$\begin{array}{l}\text { Statistical } \\
\text { Significance }\end{array}$} \\
\hline & & B Coefficient & Standard Error & & & \\
\hline \multicolumn{7}{|c|}{ In the boys group } \\
\hline \multirow{2}{*}{3} & Constant & 9.818 & 0.214 & & 45.861 & 0.000 \\
\hline & Law breaking behavior & 0.081 & 0.017 & 0.255 & 4.759 & 0.000 \\
\hline \multirow{2}{*}{3} & Constant & 8.720 & 0.387 & & 22.552 & 0.000 \\
\hline & $\begin{array}{l}\text { Being member of as- } \\
\text { sistant traffic police }\end{array}$ & 1.074 & 0.218 & 0.262 & 4.920 & 0.000 \\
\hline & Accident history & 0.132 & 0.059 & 0.119 & 2.234 & 0.026 \\
\hline \multicolumn{7}{|c|}{ In the girls group } \\
\hline \multirow{2}{*}{3} & Constant & 9.151 & 0.261 & & 34.997 & 0.000 \\
\hline & Aggressive behavior & 0.085 & 0.020 & 0.285 & 4.293 & 0.000 \\
\hline \multirow{3}{*}{3} & Constant & 10.913 & 0.722 & & 15.120 & 0.000 \\
\hline & $\begin{array}{l}\text { Being member of as- } \\
\text { sistance traffic police }\end{array}$ & -1.067 & 0.335 & -0.211 & -3.183 & 0.002 \\
\hline & Accident history & 0.800 & 0.253 & 0.210 & 3.156 & 0.002 \\
\hline
\end{tabular}

method contribution of each of the psychological factors effective in driving accidents can be identified.

Social variables also include type of vehicle with which the accident has occurred, time of accident, education, age, type of clothes used, being member of assistant traffic police, using computer games while driving, and bicycle riding on highways; all of which entered into the regression analysis.

As shown in Table 2, in the final stage of prediction per unit of change in the standard deviation of the first factor (law breaking problems) caused a change of 0.25 in the standard deviation of the dependent variable (attitude toward laws and rules); variable predictor of law break- ing problems has explained 0.06 of changes of driving accidents record.

The results also show that in the final stage of prediction, per unit of change in the standard deviation of the first factor (being member of assistant traffic police) caused a change of 0.26 in the dependent variable standard deviation (high-risk behavior); whereas, per one unit of change in the standard deviation of the second factor (driving accident record) created a change of only 0.12 in the dependent variable standard deviation. Therefore, the strongest predictor variable for high risk behavior is the factor of being member of assistant traffic police that has explained 0.06 of high risk behavior (Table 2).

Table 3. Fit indicators for examining the fitness of high risk behavior model

\begin{tabular}{|c|c|c|c|c|c|c|c|c|c|c|}
\hline \multirow[b]{2}{*}{ Indicator } & \multicolumn{5}{|c|}{ Absolute Indicators } & \multicolumn{4}{|c|}{ Comparative Indicators } & \multirow{2}{*}{ RMSEA } \\
\hline & $K^{2}$ & $\mathbf{P}$ & df & $\mathrm{K}^{2} / \mathrm{df}$ & GFI & AGFI & NFI & TLI & CFI & \\
\hline High risk behavior (boys) & 287.92 & 0.00 & 215 & 1.33 & 0.93 & 0.91 & 0.93 & 0.98 & 0.93 & 0.03 \\
\hline High risk behavior (girls) & 297.30 & 0.00 & 215 & 1.38 & 0.89 & 0.86 & 0.91 & 0.96 & 0.97 & 0.04 \\
\hline
\end{tabular}


The fitness of models and the comparison of their indicators in the boys and girls sample group

After formulating structural equations based on theoretical model in the Lisrel program, the analysis was carried out and the fit indicators of the initial model were examined. As shown in Table 3, the fitness of this model with the data appeared to be favorable. However, considering the model's high degree of freedom, correcting the model does not prejudice its model identification. Results related to fit indicators derived from the model's analysis are provided in Table 3. Therefore, given the values of these indicators it can be said that the high risk behavior model in both groups elicited a favorable fit. Table 3 provides a comparison of fit indicators in the boys and girls group.

\section{Discussion}

The aim of the present study was to examine psychosocial dimensions affecting high risk driving behavior in the age group of 12-17 years. In addition, this study seeks to improve theoretical insight and obtain applied implications for designing community based model to explain psychosocial factors of driving accidents for this age group.

Among psychological factors, results of simultaneous regression in the high risk behavior in the boys sample show that none of the parameters like personality dimensions, self-esteem dimensions or parental styles were able to predict high risk behavior. Results of stepwise regression in the final stage show that three factors such as national religious identity, attitude toward laws and rules, and aggression were able to predict high risk behavior in the boys sample with coefficients of B, 0.24 , 0.16 and 0.12 , respectively, while the strongest predictor of high risk behavior is national religious identity.

Results of simultaneous regression in the high risk model in the girls sample also show that none of the parameters like personality dimensions, self-esteem dimensions, and behavioral problems dimensions can predict high risk behavior. Results of stepwise regression in the final stage show that the two factors, namely authoritarian parenting style and attitude toward laws and rules can predict high risk behavior in the girls sample and have coefficients of $\mathrm{B}, 0.19$, and 0.18 , respectively, while the strongest predictor of high risk behavior is the authoritarian parenting style.

Among social factors also, results of stepwise regression show that participation in the plan to cooperate with traffic police with Beta coefficient of 0.26 is the stron- gest predictor of high risk behavior in adolescent boys Moreover, participation in the plan to cooperate with traffic police and a background of having been involved in driving accidents can predict the high risk behavior of adolescent girls. Participation in the plan to cooperate with traffic police with Beta coefficient of 0.21 is the strongest predictor of high risk behavior.

Results of the study conducted by Souri, Eini, Montazeri, Omidvari, Jahangiri, and Shiran (2010) entitled "The Role of Assistants Traffic Police on the Rate of Traffic Violations and Accidents of the Country" showed that after implementing the plan to cooperate with traffic police, a decline of up to 17.9 percent was observed in the level of traffic violations. The most frequent cases resulting in reduction of traffic violations were related to eating and drinking while driving. In the plan to cooperate with traffic police, training was mostly concentrated on violations such as failure to fasten the safety belt, speaking on cell phones while driving, speaking with others while driving, and eating while driving [23].

Results of the study on the model for boys involved in driving accidents show that aggression can predict high risk behavior, which is consistent with previous studies. An earlier study has shown that aggression is one of the causes that create many risks during driving [11]. Findings also show that younger men (between the ages of 18 to 24) commit "anger on the road" three times more than women of the same age group. Younger drivers, as compared with older drivers, have more negative attributes; these results also indicate the role of cognitive processing in aggressive driving behavior [24].

Gender is also very important in the expression of anger and aggression in driving accidents. Male drivers found to be involved more in high risk behaviors on roads and in traffic violations; they also pay more traffic fines and have a higher rate of involvement in motor vehicle accidents [25]. Report also suggests that hostile traffic violations, independent of demographic variables, have a significant share in driving accidents [26].

Several studies indicated that social attitudes such as attitude toward laws and rules, attitude toward police, attitude toward traffic violations, aggression, social satisfaction, and national religious identity perception affect driving accidents $[27,28]$. Consistent with the previous findings this study also shows that national religious identity, being proud of one's own nationality, and intentions to follow religious instructions are among the strongest factors to predict high risk driving behaviors in adolescent boys. The importance of these factors is un- 
derstandable since people in their adolescence try to find their own identity and seek for a role model whom they can emulate to pattern their own behavior, in which case a stability prevails in adolescence and their compatibility with the laws and rules increases.

Results of the study in both girls and boys groups show that the factor, attitude toward laws and rules can predict high risk behavior. Attitude toward laws and rules was investigated and assessed through questions regarding the adolescents' attitude toward police, observing traffic laws, his/her opinion regarding cooperation with the police, his/ her beliefs regarding the training of laws to prevent driving accidents, and his/her opinion regarding the cause of driving accidents. A study by Javadi and colleagues (2017) has shown that young people believe that "law is not effective and deterrent or it is not enforced or sometimes it can be circumvented." Given this fact, proper teaching of laws and up gradation of the existing laws based on field studies within shorter time intervals is necessary.

Accordingly, culture building should be considered from the early age in schools and subsequently in universities in a continuous and integrated manner to teach cautiousness, discipline, and obeyance of laws and rules [29]. Results of the present study are fully explicable in the form of a planned behavior model. According to the planned behavior model, the more positive the individual's attitude toward the consequences of his/her behavior and he/she feels that he/she is controlling the conduct of behavior, more likely he/she would decide about modifying the behavior. When the individual gains real control over his/her behavior it is expected that as soon as the conditions met, the individual will take his decision. Adolescents' attitude toward driving has been discussed as a factor that determines their style of driving.

Driving style means the manner by which an individual chooses to drive or habitually drives. In this regard, the planned behavior theory assumes that "intent" is the prime determinant for high risk driving. The planned behavior theory has been able to predict driving at unauthorized speed [12]. Driving at unauthorized speed is one of the most common driving violations in Iran with higher level of severity of disability. As a result, incidence of deaths due to high-speed driving is much higher than that in any other type of driving accidents [4].

Since the planned behavior theory [12] confirms that the individuals' intent to behave in a certain way is related to the number of behaviors the individuals have, the adolescents intent for driving in a high risk manner is a possible indicator for high risk driving. Usually, high risk driving is described as a behavior in which the possibility of the individual to be involved in a traffic accident is increased [30]. Our study shows that interventions or deterrents related to high risk driving and its negative consequences are effective when efforts are taken to change the attitude and intent of individuals $[5,13]$.

The present study confirms the role of attitude toward laws and rules. Accordingly, it is recommended that educational programs and messages should be designed, formulated, and conveyed to public with the special aim of changing attitude among adolescents and youngsters toward, for example, behavioral consequences of driving at unauthorized speed. Also, based on this model, with the aim of influencing the identified variables of this study, an effective step can be taken through interventional programs to reduce driving speed among adolescents and youngsters in Iran.

Considering the importance of aggression and law breaking behavior among adolescents, it is recommended to take measures in an aim to reduce possible risks and damages, before issuing driving license and during school education, applied trainings strategy, continuous and attractive, should be considered for adolescents centering on change of attitude and driving behavior. By identifying high risk behavior of students in schools, steps should be taken to psychologically assess them before they obtain a driving license. Moreover, high risk or aggressive drivers who need training or counseling should be placed under educational programs.

\section{Conclusion}

Generally, adolescent drivers suffer from misconception in understanding risk and in assessing their driving skills. Adolescents usually underestimate risks in some of the traffic situations, overestimate their ability in driving skills, and consider themselves immune toward unpleasant consequences [5]. Aggression and law breaking behaviors are considered abnormal behaviors that underlie legal problems, create delinquency, substance use and other destructive behaviors, and consequently cause injury and physical disability in adolescents and others. Furthermore, involvement of adolescents in aggressive behavior can play a role in creating and exacerbating new behavioral problems which are conveyed without any change to the later stages of their life.

\section{Acknowledgments}

This article was part of a major project entitled "Designing and Implementing Psychosocial Interventions to 
Reduce Driving Risk Factors in Adolescents and Youngsters in the City of Tehran", with financial support from UNICEF and the Red Crescent Society. We express our gratitude towards the UNICEF representative in Iran and to the Red Crescent Youth Organization for their support.

\section{Conflict of Interest}

The authors declared no conflicts of interest

\section{References}

[1] Sanaeinasab, Hormoz. Irani, Ghodratullah. Rafati, Shaldehi, Hassan. Karimi, Ali Akbar. [Investigating frequency and factors affecting driving accidents at a military center in Tehran (Persian)]. Pazhoohesh-ha-ye Modiriat-e Entezami. 2009; 4(1):19-30

[2] World Health Organization. Global status report on road safety 2013: supporting a decade of action. Geneva: World Health Organization; 2013.

[3] Office of Infrastructural Studies in Islamic Parliament Research Center. [Fatalities caused by driving accidents on the roads of Iran. Thematic code 250 (Persian)]. Tehran: Islamic Parliament Research Center; 2013.

[4] Moradi S, Khademi A, Javartani M. [Victims of traffic accidents in the decade 2001-2010 in Iran, from the point of view of statistics (Persian)]. Tehran: Legal Medicine Research Center; 2012.

[5] Deery HA. Hazard and risk perception among young novice drivers. Journal of Safety Research. 1999; 30(4):225-36. doi: 10.1016/s0022-4375(99)00018-3

[6] Norris FH, Matthews BA, Riad JK. Characterological, situational, and behavioral risk factors for motor vehicle accidents: a prospective examination. Accident Analysis \& Prevention. 2000; 32(4):505-15. doi: 10.1016/s0001-4575(99)00068-8

[7] Legal Medicine Research Center. [Number of deaths among young people due to driving accidents (Persian)]. Tehran: Legal Medicine Research Center; 2014.

[8] Masoudi Farid H. [Women and social violence (Persian)] Paper presented at: The Conference on Women in the Path of Development With Emphasis on the Sixth Development Plan; 2014 January 26; Tehran, Iran.

[9] Esfandiari, Gh (1995). [Studying the parenting practices of mothers of children with behavioral disorders and mothers of normal children and the effect of mothers' education on behavioral disorders in children (Persian)]. [MSc. thesis]. Tehran: Iran University of Medical Sciences.

[10] Hajati FS, Akbarzadeh N, Khosravi Z. [The effect of education of the combined program of cognitive-behavioral therapy with positive approach on prevention of adolescents violence in the city of Tehran (Persian)]. Quarterly Journal of Psychological Studies. 2008; 4(3):35-56
[11] Haghayegh A, Oreyzi HR. [Relation of aggression types according to Karen Horney's theory with negative and positive driving behaviors and accidents (Persian)]. Iranian Journal of Psychiatry and Clinical Psychology. 2009; 15(1):81-85

[12] Ajzen I. The theory of planned behavior. Organizational Behavior and Human Decision Processes. 1991; 50(2):179-211. doi: 10.1016/0749-5978(91)90020-t

[13] Shope JT, Bingham CR. Teen driving: Motor-vehicle crashes and factors that contribute. American Journal of Preventive Medicine. 2008; 35(3):261-71. doi: 10.1016/j.amepre.2008.06.022

[14] Morrongiello BA, Lasenby-Lessard J. Psychological determinants of risk taking by children: An integrative model and implications for interventions. Injury Prevention. BMJ; 2007; 13(1):20-5. doi: 10.1136/ip.2005.011296

[15] Yazdkhasti F, Oreyzi H. Standardization of Child, Parent and Teacher's Forms of Child Behavior Checklist in the City of Isfahan (Persian)]. Iranian Journal of Psychiatry and Clinical Psychology. 2011; 17(1):60-70

[16] Baumrind D. The influence of parenting style on adolescent competence and substance use. The Journal of Early Adolescence. SAGE Publications; 1991; 11(1):56-95. doi: $10.1177 / 0272431691111004$

[17] Buri JR. Parental Authority Questionnaire. Journal of Personality Assessment. Informa UK Limited; 1991 Aug; 57(1):110-9. doi: 10.1207/s15327752jpa5701_13

[18] Epstein NB, Baldwin LM, Bishop DS. The McMaster family assessment device. Journal of Marital and Family Therapy. 1983; 9(2):171-80. doi: 10.1111/j.1752-0606.1983.tb01497.x

[19] Nasr-Esfahani N, Etemadi A, Shafi Abadi A. [The effectiveness of meaning-centered training on family functioning of married women (Persian)]. Semi-Annual Journal of Family Counseling and Psychotherapy. 2012; 2(2):209-221.

[20] Rahiminezhad A. [Ayzenk Standardization of Adolescents Personality Questionnaire for Tehran Students 12-18 years of age Persian)]. Tehran: Ministry of Education Office of Counseling and Planning; 1993.

[21] Coopersmith, S. The antecedents of self-esteem. San Francisco: W. H. Freeman; 1967.

[22] Seifi Gandomani MY, Shaghaghi F, Kalantari Mobeidi S [The effectiveness of program of philosophy education on girl students, on their self esteem and their ability to solve problems (Persian)]. Quarterly Journal of Applied Psychology. 2011; 2(18):66-83.

[23] Suri H, Einy E, Montazeri A, Omidvari S, Jahangiri A, Shiran Gh. [The role of assistants traffic police on rate of traffic violations and accidents (Persian)]. Payesh. 2010; 9(4):339-348.

[24] Shinar D, Tractinsky N, Compton R. Effects of practice, age, and task demands, on interference from a phone task while driving. Accident Analysis \& Prevention. 2005; 37:315-326. PMID: 15667818

[25] Moskal A, Martin JL, Laumon B. Risk factors for injury accidents among moped and motorcycle riders. Accident Analysis \& Prevention. 2012; 49:5-11. doi: 10.1016/j.aap.2010.08.021

[26] Parker D, Lajunen T, Summala H. Anger and aggression among drivers in three European countries. Accident Anal- 
ysis \& Prevention. 2002; 34(2):229-35. doi: 10.1016/s00014575(01)00018-5

[27] Shakerinia I, Mohammadpoor M. [Relationship between psychological characteristics mental health, aggression and driving habits in dangerous drivers (Persian)]. Journal of Shahid Sadoughi University of Medical Sciences. 2010; 18(3):225233

[28] Hossein Javadi SM, Fekr Azad H, Tahmasebi S, Rafiei H, Rahgozar M, Tajlili A. Study of sycho-social factors affecting traffic accidents among young boys in Tehran. Iranian Red Crescent Medical Journal. 2015; 17(7). doi: 10.5812/ ircmj.22080v2

[29] Javadi SMH, Tahmasebi S, Azari-Arghun T, Arshi M, Alipour $\mathrm{F}$, et al. The youth and experience of traffic accidents (Grounded theory). Health in Emergencies and Disasters Quarterly. 2017; 2(2):79-88. doi: 10.18869/nrip.hdq.2.2.79

[30] Sümer N. Personality and behavioral predictors of traffic accidents: testing a contextual mediated model. Accident Analysis \& Prevention. 2003; 35(6):949-64. doi: 10.1016/ s0001-4575(02)00103-3 
